\title{
Patency of middle hepatic vein reconstruction using Hemashield grafts compared with ringed polytetrafluoroethylene grafts in living donor liver transplantation
}

Shin Hwang, Minjae Kim, Tae-Yong Ha, Gi-Won Song, Dong-Hwan Jung, Chul-Soo Ahn, Deok-Bog Moon, Gil-Chun Park, Young-In Yoon, Sung-Gyu Lee

Department of Surgery, Asan Medical Center, University of Ulsan College of Medicine, Seoul, Korea

Background: Because of supply shortage for homologous vein allografts, we had used ringed Goretex vascular grafts for middle hepatic vein (MHV) reconstruction in living donor liver transplantation. However, owing to unavailability of ringed Gore-Tex grafts, we replaced them with Hemashield vascular grafts. This study aimed to compare the patency and complication of Hemashield grafts with that of ringed Gore-Tex grafts.

Methods: This was a retrospective double-arm study between the study group that used Hemashield grafts $(n=157)$ and the propensity score-matched control group that used ringed Gore-Tex grafts $(n=157)$.

Results: In the Hemashield and Goretex groups, the mean recipient age was $54.7 \pm 9.4$ years and $53.3 \pm 6.3$ years; model for endstage liver disease score was $15.9 \pm 9.2$ and $16.9 \pm 8.3$; and graft-recipient weight ratio was $1.07 \pm 0.24$ and $1.10 \pm 0.23$, respectively. In the Hemashield group, V5 reconstruction was done in single $(n=113,72.0 \%)$, double $(n=39,24.8 \%)$ and triple $(n=2,1.3 \%)$. The proportions of double or triple anastomosis for V5 or V8 were higher in the Hemashield group. Two patients (1.3\%) required MHV conduit stenting owing to early thrombosis of the Hemashield conduit. There was no difference in conduit occlusion-free patient survival rate between two groups $(P=0.91)$. The incidence of conduit migration was 0 and $2(1.3 \%)$ in the Hemashield and Gore-Tex groups, respectively.

Conclusions: MHV reconstruction using Hemashield grafts demonstrated acceptably high short- and mid-term patency rates with no incidence of conduit migration and easy handling and wide flexibility in length adjustment. Therefore, we suggest that Hemashield graft is the most preferable prosthetic material for MHV reconstruction.

Corresponding author: Shin Hwang

E-mail: shwang@amc.seoul.kr

(c) The Korean Society for Transplantation

This is an Open Access article distributed under the terms of the Creative Commons Attribution Non-Commercial License (http://creativecommons.org/licenses/by-nc/4.0/) which permits unrestricted non-commercial use, distribution, and reproduction in any medium, provided the original work is properly cited. 